\title{
Thermal and Optical Studies of Rare Earth Doped Tungston-Tellurite Glasses
}

\author{
D. Sushama and P. Predeep
}

\begin{abstract}
The goal of this work is to prepare and characterize rare earth doped Tungston- Tellurite glasses. Tellurite glasses are well known for their use in optical fibre communication system, device technology etc. These glasses are stable at room temperature, and have good thermal, mechanical and optical properties. $\mathrm{Er}_{2} \mathrm{O}_{3}$ and $\mathrm{Gd}_{2} \mathrm{O}_{3}$ doped $\mathrm{TeO}_{2}-\mathrm{WO}_{3}-\mathrm{La}_{2} \mathrm{O}_{3}$ and $\mathrm{TeO}_{2}-\mathrm{WO}_{3}-\mathrm{PbO}$ glasses are prepared from high purity oxides mixtures, melting in an alumina crucible in air atmosphere. Differential Scanning Calorimetry is used to study the thermal stability of the glass systems and UV/Vis/NIR spectroscopy is used to study the optical properties of the glasses. The glass transition temperature, Crystallization temperature, melting temperature and the variation in the optical band gap, and refractive index of these samples are calculated with the addition of $\mathrm{Er}_{2} \mathrm{O}_{3}$ and $\mathrm{Gd}_{2} \mathrm{O}_{3}$.
\end{abstract}

Index Terms-Tellurite glasses, thermal stability, optical band gap, non bridging oxygen.

\section{INTRODUCTION}

Among various oxide glasses heavy metal oxide glasses doped with rare earth elements have wide area of application such as developing photonic and signal processing devices for communication and computing applications [1]. Tellurite glasses are technologically important since they are chemically stable, have high homogeneity and are resistant to divetrification at low temperature [2]. Tellurite oxide $\left(\mathrm{TeO}_{2}\right)$ used as a host material has several advantages over other oxide glass hosts and the most important one is being its low phonon frequency. $\mathrm{TeO}_{2}$ glasses are known to be low melting and high refractive index materials, therefore considered to be potential nonlinear materials [3].Their highest refractive indices among oxide glass in the visible and near IR region cause that the $\mathrm{TeO}_{2}$ based glass systems are the most promising materials in optoelectronic devices [4]. The relatively high refractive index is a consequence of high polarizability of Tellurium ions. Due to the same reasons, they also possess large third order non-linear optic susceptibilities, which are about 100 times higher than in case of traditional silicate glasses [5]. They are used in infrared optics, optical electronics, and magneto- optics as well as in optical wave guide technology [6]. Erbium doped fiber amplifiers composed of Tellurite glasses provide a wider band width than Erbium doped silica based amplifiers [7]. Their unusually large infrared transparency, high linear and

Manuscript received November 2, 2013; revised January 23, 2014

D. Sushama is now with the LAMP, Department of Physics, NIT, Calicut, Kerala, India, on Deputation from the Department of Physics, M.S.M. College, Kayamkulam, Kerala, I ndia (e-mail: sushasukumar@gmail.com). non linear refractive indices, good thermal stability and corrosion resistance and suitability as a matrix for active element doping, represent the main justification for their continuous technological interest [8], which could be a good candidate for fibre drawing [9]. The effects of rare earth ions on the thermal stability and optical properties of Tellurite glasses have been discussed. From the differential Scanning

Calorimetry (DSC) Studies the glass transition temperature $\left(T_{g}\right)$, Crystallization temperature $\left(T_{c}\right)$,and melting temperature $\left(\mathrm{T}_{\mathrm{m}}\right)$ are estimated. Crystallization of glasses plays an important role in determining their transport mechanism, thermal stability and practical applications. The thermal stability factor defined as $\Delta \mathrm{T}=\mathrm{T}_{\mathrm{c}}-\mathrm{T}_{\mathrm{g}}$ is higher than $100^{\circ} \mathrm{C}$.There for Tellurite glasses exhibit good thermal stability and is a suitable candidate for fibre drawing. When the rare earth atoms are incorporated into the glasses they do as network modifiers with ionic bonding. Rare earth- doped Tellurite glasses are chosen because of their narrow emission bands, high quantum efficiencies, non interference with common fluorescent labels, and inertness to most organic and aqueous solvents. Optical absorption in solids occurs by various mechanisms, in all of which the photon energy will be absorbed by either the lattice or by electrons where the transferred energy is covered. It is a useful method for optical investigation of induced transitions and for getting information about the band structure and energy gap of the non- crystalline materials. My aim in this paper is to discuss the thermal stability, variations in optical band gap, and refractive index of

$$
\begin{gathered}
70 \mathrm{TeO}_{2}-25 \mathrm{WO}_{3}-5 \mathrm{La}_{2} \mathrm{O}_{3}\left(\mathrm{~S}_{1}\right) \\
70 \mathrm{TeO}_{2}-25 \mathrm{WO}_{3}-5 \mathrm{La}_{2} \mathrm{O}_{3}-\mathrm{Er}_{2} \mathrm{O}_{3}\left(\mathrm{~S}_{2}\right) \\
70 \mathrm{TeO}_{2}-25 \mathrm{WO}_{3}-5 \mathrm{PbO}-\mathrm{Er}_{2} \mathrm{O}_{3}\left(\mathrm{~S}_{3}\right) \\
70 \mathrm{TeO}_{2}-25 \mathrm{WO}_{3}-5 \mathrm{La}_{2} \mathrm{O}_{3}-\mathrm{Gd}_{2} \mathrm{O} 3\left(\mathrm{~S}_{4}\right) \\
\text { and } 70 \mathrm{TeO}_{2}-25 \mathrm{WO}_{3}-5 \mathrm{PbO}-\mathrm{Gd}_{2} \mathrm{O}_{3}\left(\mathrm{~S}_{5}\right) \text { glasses. }
\end{gathered}
$$

\section{EXPERIMENTAL}

The glass samples were prepared from powders of $\mathrm{TeO}_{2}$ (99.995\% purity, Alfa acer), $\mathrm{WO}_{3}$ (99.99\% purity, Alfa acer), $\mathrm{PbO}$ ( $99.999 \%$ purity, Alfa acer), $\mathrm{La}_{2} \mathrm{O}_{3}$ (99.99\% purity, Alfa acer) $\mathrm{Er}_{2} \mathrm{O}_{3} \quad(99.99 \%$ purity, Alfa acer), and $\mathrm{Gd}_{2} \mathrm{O}_{3}(99.99 \%$ purity, Alfa acer). Tellurite glasses were obtained by melting $15 \mathrm{~g}$ batches in alumina crucibles. In order to introduce the rare-earth ions such as $\mathrm{Er}_{2} \mathrm{O}_{3}$ and $\mathrm{Gd}_{2} \mathrm{O}_{3}$ into the tellurite glass matrix, the respective oxides of an amount of $.06 \mathrm{~g}$ have been added to the batch. Appropriate amount of materials were weighed and taken into the mortar and grounded thoroughly for homogeneous mixing. After 
thorough mixing these materials were melted in an alumina crucible at $850{ }^{\circ} \mathrm{C}$ for 30 minutes in an electrical furnace in air atmosphere. The melt was poured on to a steel plate at room temperature. Bulk samples were obtained. The amorphous natures of the samples were confirmed using X-ray diffraction technique. Differential Scanning Calorimetry (DSC) is used to study the thermal stability of the prepared samples using Mettler Toledo DSC $822^{\mathrm{e}}$.The scanning temperature was in the range of $0-600^{\circ} \mathrm{C}$ with a heating rate of $10^{\circ} \mathrm{C} / \mathrm{min} . \mathrm{UV} / \mathrm{Vis} / \mathrm{NIR}$ absorption spectra for all samples were measured at room temperature using an Avantes Ava Space 2048 spectrometer in the range 200-1000 $\mathrm{nm}$. From the absorption spectra optical band gap and refractive index of the material were calculated.

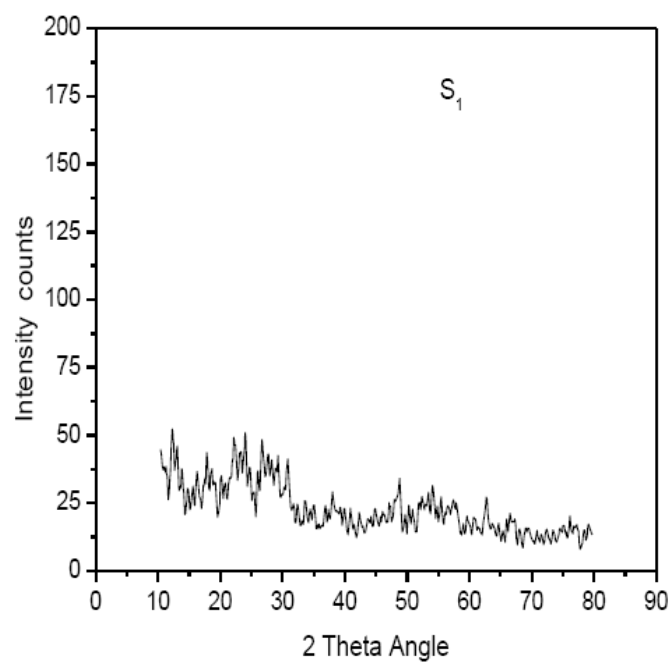

Fig. 1. XRD of a typical sample.

\section{RESULT AND DISCUSSION}

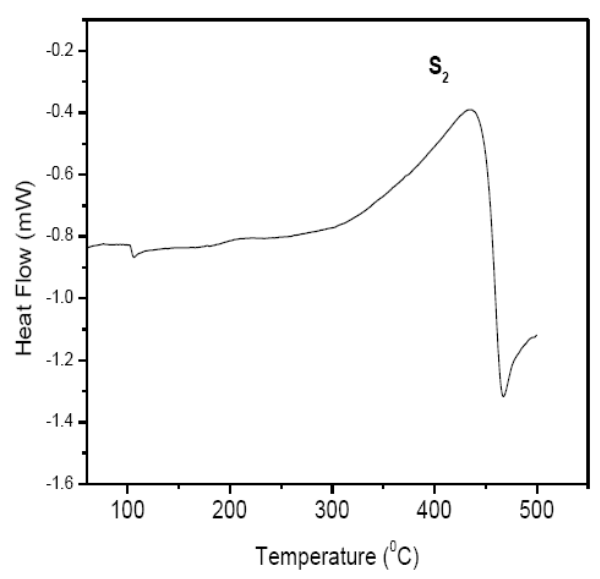

Fig. 2. DSC scans of a typical sample.

The XRD of a typical Tellurite glass $\left(S_{1}\right)$ is reported in Fig. 1 and it shows no sharp peaks resulting from the crystalline phase of the material and this confirms the amorphous nature of the material. All other samples show the same pattern of the diffraction spectra which confirms the amorphous nature of the samples. From the DSC curves Fig. 2, characteristic temperature such as glass transition temperature $\left(\mathrm{T}_{\mathrm{g}}\right)$, Crystallization temperature $\left(\mathrm{T}_{\mathrm{c}}\right)$, and melting temperature $\left(\mathrm{T}_{\mathrm{m}}\right)$ are obtained. Thermal stability factor defined as $\Delta \mathrm{T}=\mathrm{T}_{\mathrm{c}}-\mathrm{T}_{\mathrm{g}}$ is calculated. The thermal stability parameter is the most important parameter in fibre drawing. Since the fibre drawing is a reheating process, to achieve a large working range of temperature during the sample fibre drawing it is desirable for a glass host to have $\Delta$ Tas large as possible [10]. The values of $\Delta \mathrm{T}$ for all samples are given in Table I. From the literature [11] it is found that, if the value of $\Delta \mathrm{T}$ is higher than $100^{\circ} \mathrm{C}$, the glass can be considered as thermally stable. From the value of $\Delta \mathrm{Tit}$ is found that for all samples the value of $\Delta \mathrm{T}$ is higher than $300^{\circ} \mathrm{C}$. Therefore these samples are suitable for fibre drawing. Among these samples, sample $4\left(\mathrm{~S}_{4}\right)$ has higher thermal stability. From the data it is found that Tellurite glasses containing $\mathrm{La}_{2} \mathrm{O}_{3}$ are thermally more stable than the Tellurite glasses containing $\mathrm{PbO}$.

The variation in optical band gap and refractive index of glasses with composition are studied from the UV/Vis/ NIR absorption spectra. The number of electrons excited into the conduction band is a function of both the temperature and the magnitude of the energy band gap $\mathrm{E}_{\mathrm{g}}$, which is defined as the separation between the maximum energy in the valence band and the minimum energy in the conduction band. If $\mathrm{E}_{\mathrm{g}}$ is small $(0-3 \mathrm{eV}$ or $4 \mathrm{eV})$ a material is considered to be semiconductor if $\mathrm{E}_{\mathrm{g}}$ is large (4-12eV) a material is considered to be an insulator. As the electrical and optical properties are depending on the energy gap these data are very important in semiconductor device design. The study of the optical absorption edge in UV-region has proved to be a very useful method for elucidation of optical transitions and electronic band structure of materials. The optical band gap of the samples are calculated from absorption spectra, using the formula [12]

$$
\alpha h v==\left[A\left(h v-E_{o p t}\right)^{n}\right] / h v
$$

where $\alpha$ is the absorption coefficient, $h v$ is the incident photon energy, $\mathrm{A}$ is a constant and $E_{\text {opt }}$ is the optical band gap. The value of $n=2$ corresponds to indirect allowed transitions and $n=1 / 2$ corresponds to direct allowed transition Fig. 8 represents the variation of $(\alpha h v)^{2}$ versus $h v$ for indirect transitions and Fig. 9 represents the variation of $(\alpha h v)^{1 / 2}$ versus $h v$ for direct transitions. The $E_{\text {opt }}$ values with an accuracy of $+\_0.01 \mathrm{eV}$ obtained by extrapolation to $(\alpha h v)^{2}=$ 0 for indirect allowed transitions and $(\alpha h v)^{1 / 2}=0$ for direct allowed transitions. The values of $E_{\text {opt }}$ for indirect and direct allowed transitions are given in Table (1).Its value shows that these glasses have direct band gap since the value of $E_{\text {opt }}$ for indirect band gap exceeds the value of $E_{\text {opt }}$ for direct band gap [13].

The optical band gap of the five samples are found to be lower than the pure $\mathrm{TeO}_{2}$ glass of value $3.79 \mathrm{eV}$ reported in reference [14].The optical band gap of the Tungston -Tellurite glass sample $\left(S_{1}\right)$ is found to be higher than that containing rare earth ions. This reflects the influence of rare earth ions in the optical properties of rare earth ion doped Tellurite glasses. The optical band gap decreases with the addition of $\mathrm{Er}_{2} \mathrm{O}_{3}$ and $\mathrm{Gd}_{2} \mathrm{O}_{3}$. This is due to the presence of modifiers. The reduction of band gap after rare earth doping is attributed to the structural changes that are taking place in the glass with the incorporation of rare earth elements which act as the modifiers. The study of variation of optical band 
gap with $\mathrm{Er}_{2} \mathrm{O}_{3}$ and $\mathrm{Gd}_{2} \mathrm{O}_{3}$ composition gives information regarding the structure and the nature of bonds [13]. All values are given in Table I, Fig. 3, Fig. 4, Fig. 5, Fig. 6 and Fig. 7 shows absorption spectrum of $S_{1}, S_{2}, S_{3}, S_{4}$ and $S_{5}$.

TABLE I: VALUES OF OPTICAL BAND GAP, $\triangle$ T AND REFRACTIVE INDEX OF

\begin{tabular}{lllll}
\multicolumn{5}{c}{ THE SAMPLES } \\
\hline \hline Sample & Optical Band & Optical & $\Delta \mathrm{T}=$ \\
Name & $\begin{array}{l}\text { gap } \\
\text { (indirect) }\end{array}$ & $\begin{array}{l}\text { Band gap } \\
\text { (direct) }\end{array}$ & $\left(\mathrm{T}_{\mathrm{c}}-\mathrm{T}_{\mathrm{g}}\right)^{0} \mathrm{C}$ & $\begin{array}{l}\text { Refractive } \\
\text { index }\end{array}$ \\
& & & & \\
\hline
\end{tabular}

\begin{tabular}{lcccc}
$\mathrm{S}_{1}$ & 3.08 & 2.3 & 333 & 2.377 \\
& & & & \\
$\mathrm{~S}_{2}$ & 2.91 & 1.96 & 330 & 2.421 \\
& & & & \\
$\mathrm{~S}_{3}$ & 2.94 & 1.965 & 318 & 2.413 \\
& & & & \\
$\mathrm{~S}_{4}$ & 3 & 2 & 338 & 2.3971 \\
& & & & \\
$\mathrm{~S}_{5}$ & 3.03 & 2.07 & 313 & 2.389 \\
\hline
\end{tabular}

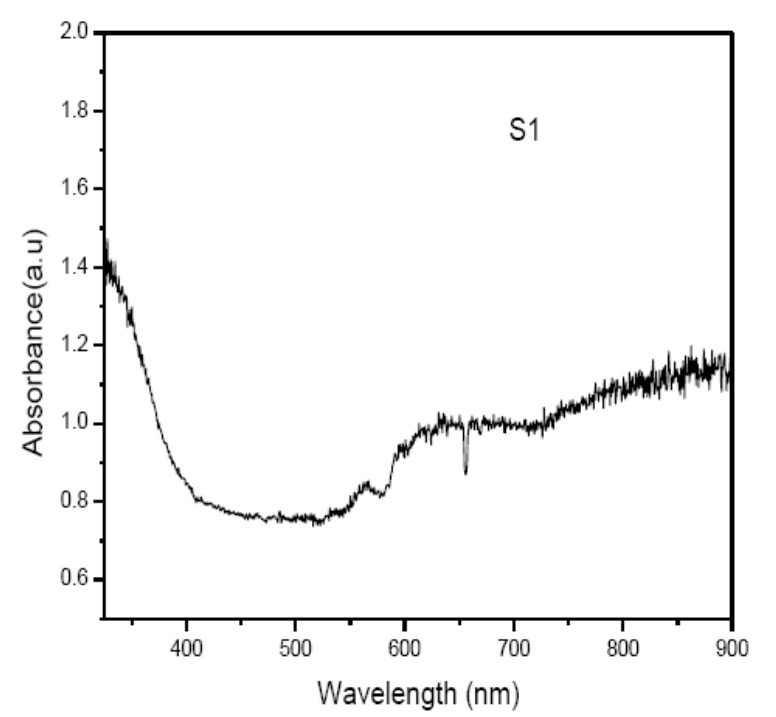

Fig. 3. Absorption spectra of sample (S1).

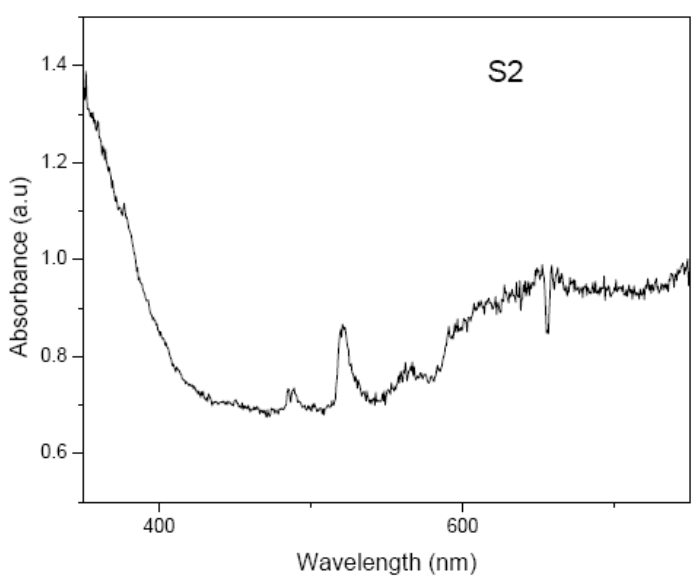

Fig. 4. Absorption spectra of sample (S2).

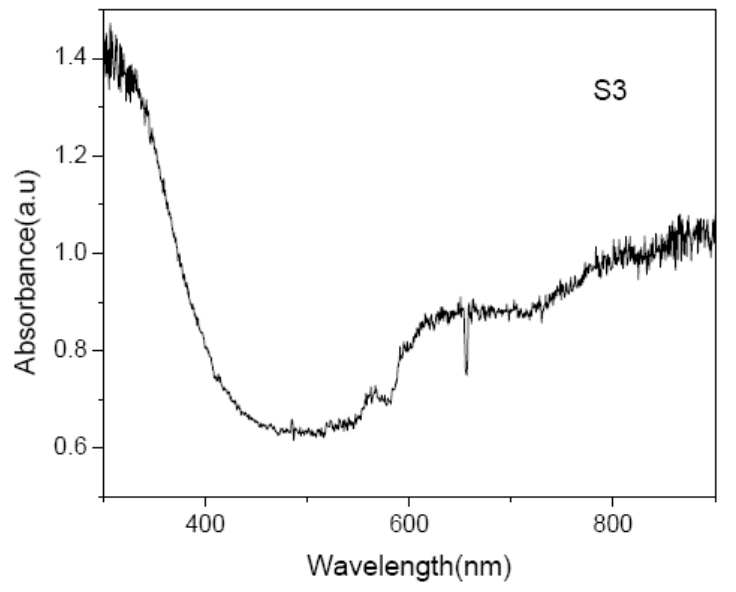

Fig. 5. Absorption spectra of sample (S3).

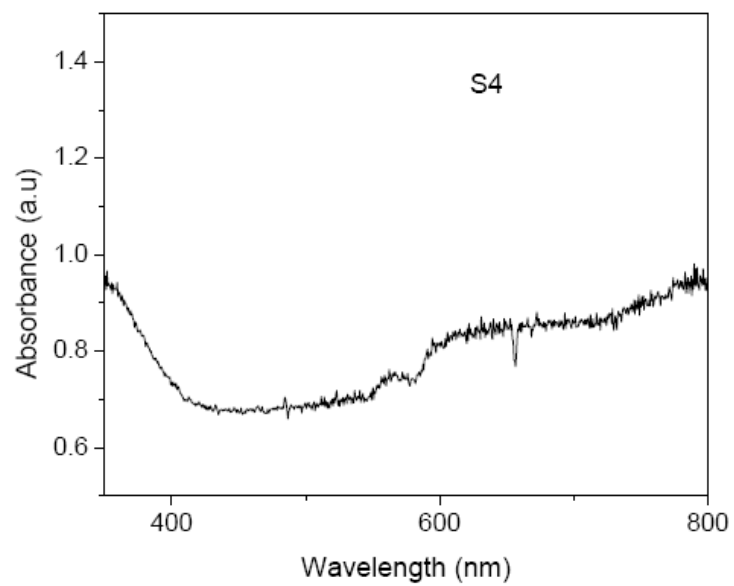

Fig. 6. Absorption spectra of sample (S4).

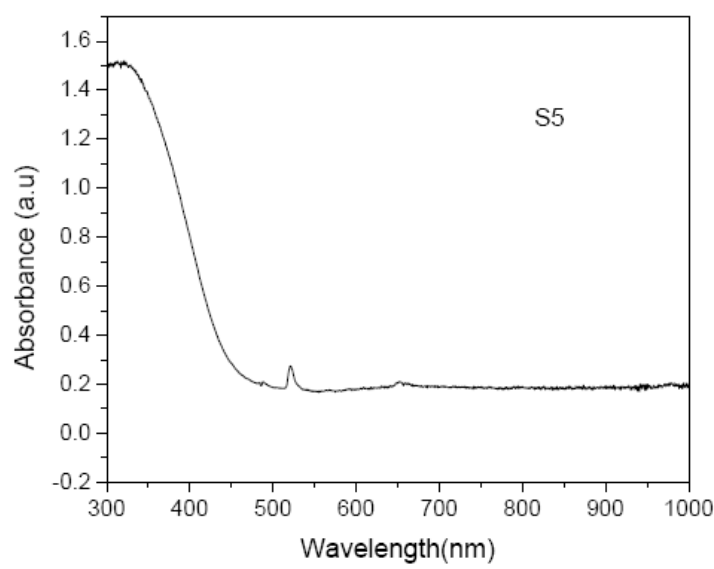

Fig. 7. Absorption spectra of sample (S5).

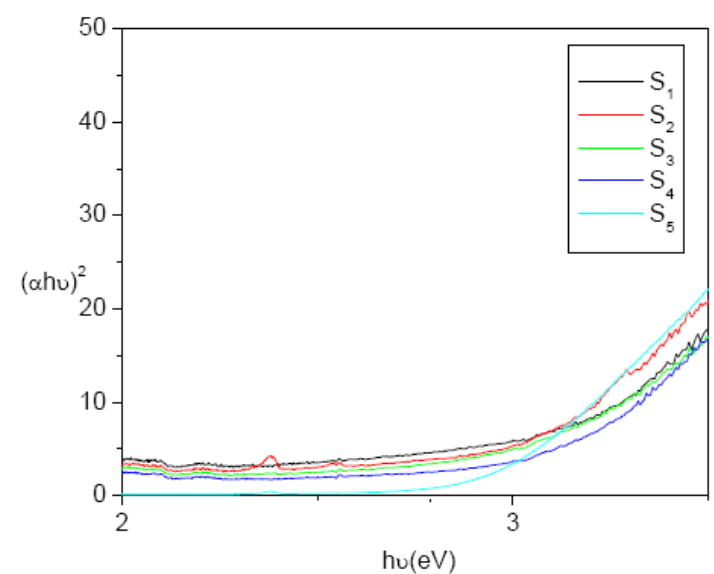

Fig. 8. Plot of ( $\alpha$ hv)2 versus hv. 


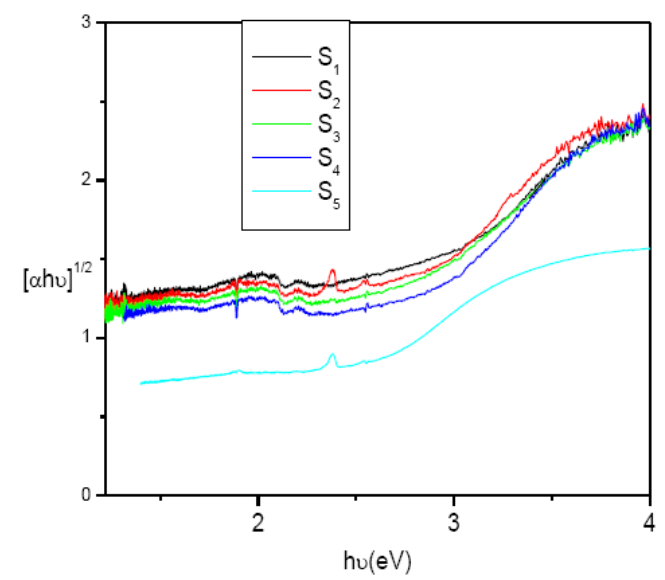

Fig. 9. Plot of $(\alpha$ hv) $1 / 2$ versus hv.

The introduction of RE ions changes the oxygen bonding in glass forming network and any change of oxygen bonding in glass forming network such as formation of Non Bridging Oxygen changes the absorption characterics which accordingly decreases the optical band gap. When rare earth is introduced into the Tellurite matrix, its coordination number changes. The optical band gap is influenced not only by a chemical composition but also by a structural arrangement of the sample matrix [13]. When $\mathrm{Er}_{2} \mathrm{O}_{3}$ is replaced by $\mathrm{Gd}_{2} \mathrm{O}_{3}$ the increase in optical band gap is due to the replacement of Er-O bond by $\mathrm{Gd}-\mathrm{O}$ bond. The increase in optical band gap with $\mathrm{Gd}_{2} \mathrm{O}_{3}$ content can be explained with the movement of electron density [15]. When $\mathrm{Gd}_{2} \mathrm{O}_{3}$ is added instead of $\mathrm{Er}_{2} \mathrm{O}_{3}$ in the samples the number of Non-Bridging Oxygen decreases which accordingly increases the optical band gap [13]. The reduction in the number of Non-Bridging Oxygen is due to the value of molar mass of the materials. The molar mass of $\mathrm{Gd}_{2} \mathrm{O}_{3}$ is less compared to the molar mass of $\mathrm{Er}_{2} \mathrm{O}_{3}$. Again from the study of optical band gap, the value of optical band gap containing $\mathrm{PbO}$ is higher than that containing $\mathrm{La}_{2} \mathrm{O}_{3}$. This is because the molar mass of $\mathrm{PbO}$ is less than that of $\mathrm{La}_{2} \mathrm{O}_{3}$. There for there is a reduction in the number of Non Bridging Oxygen atoms and this in turn increase the value of optical band gap for the samples containing $\mathrm{PbO}$.

The refractive index is calculated for all the samples and it is found to be higher than 2.39 within the $400-475 \mathrm{~nm}$ spectral range which are considerably higher than those obtained for standard optical glasses [16].Doping of rare earth atoms increases the refractive index. High values of refractive index of Tellurite glasses allow using such material in optical wave guides, where a self focusing effect is observed. [6], [17]. The relationship between refractiveindex ' $n$ ' and the optical energy gap is examined by the equation [18]

$$
\frac{\left(n^{2}-1\right)}{\left(n^{2}+2\right)}=1-\sqrt{E_{g} / 20}
$$

The addition of rare earth ions to the network leads to the formation of dense packing of rare earth modifiers into the host materials [19]. These have a direct effect on increasing the refractive index, because of the direct proportional relationship between dense packing and the refractive index.
High refractive index of these glass samples are attributed to the high polarization of host material $\mathrm{TeO}_{2}$ [18]. Doping of $\mathrm{Gd}_{2} \mathrm{O}_{3}$ instead of $\mathrm{Er}_{2} \mathrm{O}_{3}$ to a Tellurium matrix results in the reduction of refractive index of the glass. Non bridging Oxygen also has an effect on the refractive index, because the polarity of Non Bridging Oxygen is higher than that of Bridging Oxygen [20].

\section{CONCLUSION}

Rare earth doped Tungston-Tellurite glasses are prepared by melting and quenching techniques. Since the value of $\Delta \mathrm{T}$ is higher than $100^{\circ} \mathrm{C}$, the glass can be considered as thermally stable. The optical band gap of the Tungston-Tellurite glass sample $\left(S_{1}\right)$ is found to decrease with the addition of rare earth ions. The optical band gap depends on the number of Non-Bridging Oxygen produced. The refractive indexes of all samples are considerably higher than those obtained for standard optical glasses.

\section{ACKNOWLEDGMENT}

The authors acknowledge University Grants commission for supporting this work financially under the research awardees scheme.

\section{REFERENCES}

[1] T. Komatsu, H. Tawarayama et al., J. Non Crystalline Solids, vol. 135, no. 105,1991

[2] Y. Shalout, R. Tang et al., J. Phys. Chem. Solids, vol. 56, no. 1, pp. 141-150, 1995.

[3] V. V. R. Kumar, A. George, and J. Knight, RusselPsjOptexp, vol. 11, p. 2641, 2003

[4] P. Hagenmuller, Inorganic solid fluorides, Chemistry and Physics, New York: Academic Press, 1985.

[5] E. P. Golis, M. Reben, J. Wasylak, and J. Filipecki, Optica Applicata, vol. XXXVIII, no. 1, 2008

[6] M. Reben, J. Wasylak, and D. Dorosz, in Proc. Spie, vol. 7120, 2008.

[7] I. V. Kityk, N. S. Alzayed et al., Optics Communications, vol. 285, pp. 655-658, 2012.

[8] E.-M. Rah, Tellurite Glasses handbook- physical properties and data, CRC, Boca Raton, FL, 2001.

[9] J. M. Jewell, L. E. Busse et al., in Proc. SPIE, vol. 2287, p. 154, 1994

[10] L. Neinde, S. Jiang, and B. J. Hwang, JNCS, vol. 255, no. 97, 1999.

[11] J. S. Wang, E. M. Vogel, and E. Snitzer, Opt. Mater, vol. 3, p. 187, 1994.

[12] J. Tauc, Amorphous and liquid Semiconductors, New York: Plenum, 1974.

[13] I. Jlassi, H. Elhouichet, and M. Ferid, J. Mater Sci, vol. 46, pp. 806-812, 2011.

[14] V. Dimitrov and S. Sakka, J. Appl. Phys., vol. 79, 1996, p. 1736.

[15] B. Yasser et al., Solid State Sciences, vol. 12, pp. 1426-1434, 2010.

[16] B. Burtan, M. Reben, J. Cisowski, J. Wasylak, N. Nosidlak, J. Jaglarz and B. Jarzabek, Actaphysicapolonica, vol. 120, pp. 579-581, 2011.

[17] E. M. Vogel, M. J.Weber, and D. M. Krol, Phys. Chem., Glasses, vol. 32, pp. 231-235, 1991.

[18] I. A. Ahmed et al., Materials Chemistry and Physics, vol. 109, pp. 291-296, 2008.

[19] J. Yasi, J. Fusong, and F. Gan, Chin. Phys., vol. 3, p. 162, 1983.

[20] Y. Chen et al., "A study of nonlinear optical properties in $\mathrm{Bi}_{2} \mathrm{O}_{3}-\mathrm{WO}_{3}$ - $\mathrm{TeO}_{2}$ glasses," J. Non-Cryst. Solids, vol. 354, pp. 3468-3472, 2008.

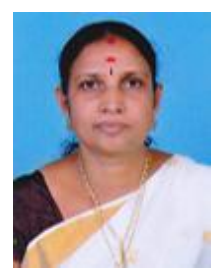

D. Sushama was born in Harippad, Alappuzha (Dist), Kerala (state) India on July 15, 1963. She got her M.Sc Physics, Kerala University, Kerala State, India in 1988 , M.Phil. (Specialization Spectroscopy) Kerala University, Kerala State, India in 1995, and Ph.D (material science) Kerala University, Kerala State, India in 2008. Her major field of study is material science.

She is now working as an associate professor in the 
Department of Physics M.S.M College, Kayamkulam, Kerala (state), India from 1995 onwards. Sheposses a remarkable research profile too. She has more than 19 scientific publications. Her current work is to develop chalcogenide glass-polymer composite for photonics applications. Her previous area of research was study on the transport properties of chalconogenide glasses.

She is the member of Indian Science Congress Association. She was awarded the Best oral presentation award in ISRS in 2006 from IIT Chennai.

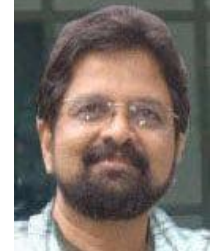

P. Predeep was born in Mavelikara, Alappuzha (Dist), Kerala (state) India on April 8, 1958. He obtained his Ph.D from University of Rajasthan. His major field of study is unconventional electronics and photonics.

$\mathrm{He}$ is now working as a professor in the department of Physcis, National Institute of Technology, Calicut, Kerala, India, Pin-673601 since 2007onwards. He poses a remarkable research profile too. He has more

than 210 scientific publications including books and book chapters and six patents to his credit.

He is a member of IEEE, Optical Soceity of America, (OSA), SPIE, and Indian Society for the Scientists of Disordered Materials. 